\title{
The Present Situation and Trend of Wearable Equipment in Electric Field Application
}

\author{
Shao Guangwei, Ji Zhongjun, and Liu Bing \\ Economic and Technological Research Institute, Liaoning Electric Power Co., Ltd. State Grid (Liaoning Electric Power \\ Construction Supervision Co., Ltd), Shenyang, China
}

\begin{abstract}
With the innovation of mobile internet technology and intelligent terminal technology, the wearable equipment has been gradually applied in various industries. Through the typical application of wearable equipment, the characteristics of wearable equipment technology and application are summarized. Based on the analysis of power field business application and technology, combined with the demand of electric field management, the design situation of the wearable equipment in electric field service is designed, and the future development direction of electric field wear can be forecasted.
\end{abstract}

\section{Introduction}

The wearable equipment refers to the use of wear technology for daily wear intelligent configuration of the equipment. All kinds of sensing, identification, connectivity and cloud services and other technologies are integrated into people's glasses, rings, watches, bracelets, clothing and footwear and other daily wear equipment in order to achieve the user five sense of ability to expand, life steward, social entertainment, health monitoring and other functions. The general appearance of the equipment is more beautiful and easy to wear, with a certain degree of computing power and have a dedicated application and function and so on.

As a portable and wearable computing device, the wearable equipment has miniaturization, portable, small size and mobility and other characteristics. Therefore, being different from the general computing equipment or smart devices in the human-computer interaction, the wearable equipment is a kind of human machine directly seamless, fully connected to the interactive way; its main features include single (double) hand release, voice interaction, perception enhancement, tactile interaction, consciousness interaction and so on.

\subsection{Perception}

The wearable equipment can promote people's perception of the world, others, and us. We can perceive the world through wearable equipment. For example, smart glasses can help us to identify the animals and plants, smart chopsticks can help us to perceive the food contains nutrients, even through the wearable equipment to read the meaning of other people's micro-expression, understand the language of their pets, the wearable equipment provides human beings with the infinite possibilities of perceiving the world[1].

\subsection{Management}

The wearable equipment can help people achieve the control of other electronic equipment, achieve the location of the records and allow us to visually see a good line planned by us through the sensors. The progress of the project and the control of the own act can also be achieved. The wearable equipment can not only achieve the control of other equipment, but also achieve the control functions move to the person's body from the original mobile phone or computer. So that the function is more intuitive and life is simpler.

\subsection{Expression}

Because the wearable equipment is portable, so the expression is more convenient, more image and more accurate in the process of communication achieved by projection, display, three-dimensional imaging and file transfer, etc.

\section{Wearable equipment applications}

The development and application of wearable technology puts more demands on the portability and mobility of the device. As an important basis for field management and means, the wearable equipment effectively complete the realtime recording and online control combined with the special nature of industry and professional, fully playing portability and real-time characteristics[2].

The wearable equipment directly wearing by the human body determines its three main features:

- Human relevant data can be obtained by it, powerful and small size.

\footnotetext{
Corresponding author: sy_liangqian@sina.com
} 
- Solve the most direct needs, simple and easy to use, strong affinity.

- Beautiful, small, comfortable and suitable.

Wearable equipment is mainly used in personal health, medical services, environmental protection, fitness, recreation and other industries. The use of its own high portability, high mobility and high timeliness, the excellent application result has been accessed[3].

\subsection{Medical field}

In the medical field, the wearable equipment will be in vitro data collection and cross-analysis through data collection to help users to manage important physiological activities, to make the monitoring of various health indicators. Wearing medical care allows patients to manage their own diseases.

The current application of wearing equipment in the medical field is mainly reflected in two aspects: one is in vitro data collection, mainly through the G-sensor with threedimensional motion sensor or GPS to obtain movement distance and exercise, to help users to exercise and manage sleep, while introduce the concept of social platform for users to measure and contrast the data between different users to promote the user's continue behavior and to change the health of users. The other is to help users manage important physiological activities by means of sign data such as heart rate, pulse rate, respiratory rate, body temperature, heat consumption, blood pressure, blood glucose and blood oxygen, hormones and BMI index, body fat content. The results of these numerical cross analyses can be used to analyze the user's current physical condition and health risk assessment, combined with data the several key physiological activities can be given: sleep, diet, exercise and medication personalized improvement recommendations, allowing users to stay in a stable physical conditions $[4,5]$.

\subsection{Sports field}

In the field of sports, the wearable equipment will be used in the field of physical health management and professional sports applications, including the application of ski, swimming, mountain climbing, running and other special sports areas.

At present, the wearable equipment based on sports and fitness is mainly used in two aspects: on the one hand applied to the health aspects of such products are mainly concerned with the movement of fitness crowd, they can record their daily real-time exercise, consumption of calories, food Into the amount of sleep and thus effectively urge themselves to increase the amount of exercise to maintain good health; On the other hand, applied to professional sports applications, such as skiing, swimming, mountain climbing, running and other special sports areas, for example, the wearable equipment is applied in the ski field to confirm their position in the snow, location, height, taxi speed and is applied in swimming to confirm their data such as heart rate, calorie consumption and maximum heart bear ability when athlete does not stop endurance exercise.
In the field of entertainment, the wearable equipment will be in social, games, photography, reading, Internet, APP and other aspects; it will have a wider range of applications.

Entertainment applications of the wearable equipment become part of today's social life and the inseparable part of the mobile terminal has become the main tool for users of fragmented life entertainment, similar to smart phones, PAD, wearable equipment in order to obtain public recognition. Entertainment and social applications become another key application for its future development. In the future, the wearable equipment in social, games, photography, reading, Internet, APP and other aspects will have a wider range of applications. And now the wearable equipment entertainment social field applications has become a positive development focus of the manufacturers, Google Glass can achieve unique glasses perspective of the photo and video, Samsung Galaxy Gear take pictures of photography, and support for Internet access and social information access. Japan Telepathy has introduced a wearable device that can create real-time access to social networking and cloud services, equipped with cameras, projection units and wireless communication modules, etc. The wearers can use the device to broadcast their own views and so on. Replay launched the first social function of the smart jeans products, the biggest feature is to support the Bluetooth function, jeans and smart phones and other equipment can be connected.

At present, the types and how to wear of equipment mainly include:

- Headwear: glasses, headband.

- Hand wear class: bracelet, watch, gloves.

- Clothing categories: belts, bandages, clothing.

\section{Power scene business situations}

Power site is mainly reflected in the construction, construction supervision, operation and maintenance, customer service site. In the field work the field equipment, device information must be collected and the work of the scene need be recorded, at the same time management personnel can complete the work of the scene and quality supervision and control.

At present, on the professional power scene the typical application of the wearable equipment has not been seen. Electricity major professional complete the power construction, production maintenance, marketing services, communications and other professional business data entry and collection are mainly by mobile terminals, handheld equipment and other equipment. But the power of the majority of professional business information and data processing, still rely on the PC side to complete.

Power field business mobile devices mainly include:

- Handheld Terminal: Based on commercial PDA terminals, their applications are in the power industry, mainly in power distribution and transmission line inspection applications. Its advantages are wireless communication and interactive operation of distribution line, courts information marking and collection, as well as transmission line inspection and recording. 
- Measuring instrument: In the power construction, the need to measure the site construction, construction, access to site, equipment data, Electric work personnel, the use of special measuring instruments to complete the measurement operation.

- Infrared thermal imager: In the power production site, operation and maintenance personnel regularly check the state of power equipment operation, through the equipment parameters to determine the equipment status and operating situation. The surface of the node thermal images and ensuring accurate measurement of temperature data is achieved by the use of infrared thermometer, shooting equipment.

- Meter reading device: Mainly used for power marketing on-site meter reading use. Solve the problem of manual recording of electric energy meter reading table. As the functional requirements are relatively simple, you can record the number of electricity can be. Meter reader terminal performance is relatively low, storage space is small, and the display is black and white LED.

- GPS locator: With GPS and GPRS wireless communication capabilities, mainly used in transmission, distribution professional, in the line inspection, with the power operators to complete the positioning and data upload operation.

- Digital Camera: In the construction of electric power construction site, supervision site, maintenance site, most of the need to collect on-site work of the image information, as well as equipment, personnel related images. So the power of personnel digital cameras, power scene image records.

Through the power of the professional and on-site mobile terminal equipment classification and application can be seen, the ultimate goal is to complete the power field control and business information records, thereby enhance the power business site control capabilities. The power field applications and business needs are shown in Table 1.

Table 1. Power field applications and business needs

\begin{tabular}{|c|c|c|}
\hline Profession & Main job content & Business needs \\
\hline Infrastructure & $\begin{array}{c}\text { Foundation } \\
\text { construction }\end{array}$ & $\begin{array}{c}\text { Site control, } \\
\text { personnel control }\end{array}$ \\
\hline Supervision & $\begin{array}{c}\text { Engineering } \\
\text { supervision, } \\
\text { quality management }\end{array}$ & $\begin{array}{c}\text { Site control, } \\
\text { personnel control }\end{array}$ \\
\hline Substation & $\begin{array}{c}\text { Substation } \\
\text { construction, } \\
\text { operation and } \\
\text { maintenance }\end{array}$ & $\begin{array}{c}\text { Site control, } \\
\text { personnel control, } \\
\text { equipment status } \\
\text { records }\end{array}$ \\
\hline Transmission & $\begin{array}{c}\text { Line construction, } \\
\text { inspection line, } \\
\text { operation and } \\
\text { maintenance }\end{array}$ & $\begin{array}{c}\text { Site control, } \\
\text { personnel control, } \\
\text { equipment status } \\
\text { records }\end{array}$ \\
\hline distribution & $\begin{array}{c}\text { Distribution lines, } \\
\text { Substation collection }\end{array}$ & $\begin{array}{c}\text { Site control, } \\
\text { personnel control, } \\
\text { equipment status } \\
\text { records }\end{array}$ \\
\hline Marketing & $\begin{array}{c}\text { Customer service, } \\
\text { inspection, } \\
\text { electricity } \\
\text { management }\end{array}$ & $\begin{array}{c}\text { Site control, } \\
\text { personnel control }\end{array}$ \\
\hline Communication & $\begin{array}{c}\text { Communication } \\
\text { construction, } \\
\text { operation and } \\
\text { maintenance }\end{array}$ & $\begin{array}{c}\text { Site control, } \\
\text { personnel, } \\
\text { equipment status } \\
\text { records }\end{array}$ \\
\hline
\end{tabular}

Power construction site and the number of operating sites, scattered widely, carrying work inconvenient, and thus suitable for wearable equipment applications. With the strengthening of the power field business management, as well as the improvement of data accuracy requirements, wearable equipment is small, easy to portable, and gradually requires the ability to enter more comprehensive information and content. Support a richer business, assist in the completion of on-site business control, and enhance the realtime control of power business. The wearable equipment is bound to be used in the electricity field, to replace the original handheld, portable and other equipment used to become the necessary work on the power site.

\section{The application trends}

The wearable equipment in the power industry applications are still in the initial stage, the main application of handheld terminal equipment, in the field for recording use. In the infrastructure, substation, transmission, supervision, distribution, scheduling, marketing and other management professionals, are lack of business in the field of terminal equipment. But for the power industry is an urgent need to address the field business processing and control, wearing tools and devices has not yet applied. With the power of professional management and business applications continue to deepen the demand for wearable equipment will become increasingly urgent, it can be seen the wearing equipment in the power of professional applications with considerable prospects.

The wearable equipment applications are mainly concentrated in the following areas.

\section{- On-site Supervision}

Electric field construction, construction operations, operation and maintenance, customer service, complete the field process records and monitoring, improve the quality of work, improve quality service. The wearable equipment onsite automatic recording, does not affect the normal business processing.

\section{- Personnel Control}

Personnel control, mainly infrastructure, substation, transmission site, the need for real-time monitoring of operational safety, real-time perception of the physical condition of workers, to avoid access to dangerous areas. So through the wearable equipment, the physical condition of workers is monitored real-time and the personal safety management of electricity workers are effectively strengthen to avoid casualties and supervise the scene at the same time.

\section{- Equipment Control}

In the power scene the operation of the equipment is often needed to monitor and the scene operating equipment is needed to record. The wearable equipment can operate at the same time, real-time, accurate monitor of equipment running, does not affect the normal work. 
The wearable equipment performance and functional technology innovation and development will promote the power industry wearable equipment business applications and the original power professional business and management further extend. Aiming at the visualization demand of electric field, combined with the typical application scene of wearable equipment, the technological innovation and application trend of the wearable equipment in power field is summarized.

The wearable equipment types, wear patterns and application are shown in Table 2.

Table 2. Power field applications and business needs

\begin{tabular}{|l|l|l|}
\hline \multicolumn{1}{|c|}{ Types } & \multicolumn{1}{c|}{ Pattern } & \multicolumn{1}{c|}{ Application } \\
\hline Wearing class & Glasses, headband & $\begin{array}{l}\text { Site control, } \\
\text { status records, } \\
\text { on-site control }\end{array}$ \\
\hline Hand wear class & Bracelet, watch, glove & $\begin{array}{l}\text { Personnel control, } \\
\text { safety monitoring, } \\
\text { equipment records, } \\
\text { on-site control }\end{array}$ \\
\hline Clothing category & Belts, bandages, clothing & $\begin{array}{l}\text { Personnel control, } \\
\text { safety monitoring, } \\
\text { site control, }\end{array}$ \\
\hline
\end{tabular}

\subsection{Controllable wearable equipment}

The embedded design, the formation of small equipment are used, easy to install and wear in the helmets, shoulders, eyes, arms and other parts. To meet the needs of power site safety and control, it is facilitated the work of electric power workers in the field to carry and use. The controllable wearable device integrates high-definition video capture, image processing, video storage, voice recording, communication function, efficient supervision and control of electric field personnel and equipment, and realizes power scene management and equipment management.

\subsection{Guard proof wearable equipment}

Mainly for power workers to carry out a full range of state monitoring, as well as operating personnel on-site security protection. Structural design more inclined to bracelet, watches, wristbands and other types, easy to wear at the same time, more importantly, the signs and status of the operator can accurately be recorded. So the wearing equipment must be more closely with the operator. The wearable equipment assimilated into the pulse, blood pressure, sleep, body temperature and other precision sensors monitor the physical signs of workers all the time. At the same time the electromagnetic, current, voltage sensor sensors are integrated to prevent the operation of personnel into the high pressure area and operate the full range of electrical workers effectively.

\subsection{Recording wearable equipment}

Mainly used for electric field information recording and collection, replace the PDA and other mobile terminals to complete the work of the scene. Recordable wearable equipment can be worn on the operator's arm, chest and other positions with a key operation function. According to the power scene the power scene, equipment and work conditions are recorded. At any place in the field electricity on-site work and the situation are collected all-weather realtime. The wearable equipment support the power operation personnel to record the scene situation, complete the power scene multi-dimensional data, images, data records, collection and storage.

The wearable equipment, full support for wireless communication and storage backup, complete the power field work control, record upload and storage. Configuration of large capacity rechargeable lithium battery, to ensure that wearing equipment can work longer than 12 hours. Provide both active and passive power supply, to meet the power of various field applications, to complete the wearable device in the passive environment of the power supply.

\section{Conclusions}

Power field control is an important guarantee for the stable supply of electricity. Targeted to strengthen the power site management, to meet the technical means and equipment needs, the control means are needed to strengthen. To meet the management needs of the scene and the full complete the personnel, on-site, work and equipment monitoring, and to deal with inconvenience and the not timely recording, complex operation and other issues, with its upgrading and innovation the wearable equipment is bound to promote the use of the power industry. The wearable equipment provide a more comprehensive supervision and control, strengthen the protection of workers and equipment to enhance the quality of the quality of live operations for the power field business.

\section{References}

1. Yi Geng, Hui An, Yang Li, Hua Jiang. Present Status and Future Perspectives of the Wearable Devices [J]. Electronic Science and Technology, 2014, 02: 238-245.

2. Gatzoulis L, Iakovidis I. Wearable and portable eheahh systems. Technological issues and opportunities for personalized care [J]. IEEE Eng Med Biol Mag, 2007, 26(5): 51-56.

3. Rutherford JJ. Wearable technology health-care solutions for a growing global population [J]. IEEE Eng Med Biol Mag, 2010, 29 (3): 19-22.

4. Appelboom G, Camacho E, Abraham M, et ol. Smart wearable body sensors for patient self-assessment and monitoring [J]. Arch Public Health, 2014, 72(1): 28-28.

5. Pandian PS, Mohanavelu K, Safeer KP, et al. Smart vest: wear- able multi-parameter remote physiological monitoring system [J]. Med Eng Phys, 2008, 30(4): 466-477. 